\title{
Comparison of Visual Outcome After Hyperopic LASIK Using a Wavefront-Optimized Platform Versus Other Excimer Lasers in the Past Two Decades
}

\author{
Majid Moshirfar (D) - Alin Megerdichian - William B. West • \\ Chase M. Miller • Ronald Alek Sperry · Calvin D. Neilsen • \\ Mitchell T. Tingey · Phillip C. Hoopes
}

Received: March 11, 2021 / Accepted: April 10, 2021 / Published online: May 19, 2021

(C) The Author(s) 2021, corrected publication 2021

\section{ABSTRACT}

Introduction: Laser-assisted in-situ keratomileusis (LASIK) for the correction of hyperopia and hyperopic astigmatism is challenging and has been less studied than for the correction of myopia and myopic astigmatism. The aim of this study was to analyze the refractive outcomes of LASIK in hyperopia and hyperopic astigmatic eyes using a wave-front

M. Moshirfar $(\bowtie)$. P. C. Hoopes

Hoopes Vision Research Center, Draper, UT, USA

e-mail: Cornea2020@me.com

M. Moshirfar

Moran Eye Center University of Utah, Salt Lake City, UT, USA

M. Moshirfar

Utah Lions Eye Bank, Murray, UT, USA

A. Megerdichian

College of Medicine, California Northstate

University, Sacramento, CA, USA

W. B. West

School of Medicine, University of Utah, Salt Lake

City, UT, USA

C. M. Miller

McGovern Medical School, Houston, TX, USA

R. A. Sperry · C. D. Neilsen

Brigham Young University, Provo, UT, USA

M. T. Tingey

Wake Forest School of Medicine, Winston-Salem, NC, USA optimized laser platform (the Allegretto EX500 laser) and perform a historical comparison with other excimer lasers within the past two decades.

Methods: A one-center (Tertiary Refractive Center, Draper, Utah), retrospective, non-comparative study was conducted on 379 eyes treated with LASIK for hyperopia and hyperopic astigmatism. The data retrieved on these eyes were analyzed using uncorrected distance visual acuity (UDVA), corrected distance visual acuity (CDVA), and spherical equivalents. A literature search of excimer platforms in use in the past 20 years and a comparison of US Federal Drug Administration-approved platforms for hyperopia were performed.

Results: At 3 and 12 months postoperatively, $142(66 \%)$ and $81(69 \%)$ eyes had a UDVA of 20/20 or better and $207(96 \%)$ and 114 (97\%) eyes had a UDVA of $20 / 40$ or better, respectively. The mean refractive spherical equivalent was $-0.52 \pm 0.78 \mathrm{D}$ at 3 months and $-0.46 \pm 0.79 \mathrm{D}$ at 12 months. At 12 months, $181(96 \%)$ eyes achieved a spherical equivalent within $\pm 1.00 \mathrm{D}$ of the intended target. Studies published before 2005 reported lower rates of UDVA $20 / 20$ or better (32\%) compared to those published after (68\%); however, this discrepancy was less evident for UDVA 20/40 or better. A similar trend towards improved accuracy was noted in the literature with postoperative manifest refractive spherical equivalent within $\pm 0.50 \mathrm{D}$ before and after 2005 . 
Conclusion: There has been significant improvement in safety, efficacy, stability, and accuracy of LASIK treatment for hyperopia and hyperopic astigmatism within the past two decades. Newer excimer lasers meet industry standards and in particular, the Allegretto EX500 used in this study exceeded industry standards.

Keywords: LASIK; Hyperopic astigmatism; Allegretto EX500 laser; Wave-front optimized laser platform

\section{Key Summary Points}

Laser-assisted in-situ keratomileusis

(LASIK) treatment and outcomes of hyperopia and hyperopic astigmatism is not as fully studied as LASIK outcomes for myopia and myopic astigmatic patients.

Various modern-day excimer laser platforms, not including the wavefrontoptimized platform (Allegretto EX500), have been individually studied and found to have varying degrees of safety and efficacy.

After performing a literature review on existing excimer lasers, we report a noteworthy shift in 2005 towards improved safety, efficacy, predictability, and rates of regression in eyes treated with LASIK.

In this single-center study, the Allegretto EX500 excimer laser exceeds industry standards of safety and efficacy and has significantly improved the refractive outcomes of LASIK for hyperopic patients when compared to other platforms.

\section{DIGITAL FEATURES}

This article is published with digital features, including a summary slide, to facilitate understanding of the article. To view digital features for this article go to https://doi.org/10.6084/ m9.figshare.14393708.

\section{INTRODUCTION}

While the current literature on the safety and efficacy of laser-assisted in-situ keratomileusis (LASIK) surgery contains abundant information on myopic patients, there is a relative scarcity of data on LASIK surgery for hyperopia and hyperopic astigmatism. Over the past few decades, new surgical techniques have been developed and continually refined to make refractive surgery on hyperopic eyes safer and more predictable. However, the treatment of hyperopia continues to pose a challenge to many surgeons due to reports of unfavorable outcomes, including refractive regression, undercorrection, and loss of corrected distance visual acuity (CDVA) [1, 2]. The correction of hyperopia is considered more difficult because excimer laser photoablation must induce flattening in the corneal periphery with concomitant steepening of the central optical zone, in comparison to direct flattening in the center of the cornea for myopic patients. The technique requires larger ablation zones and accurate centration for uniform delivery of energy onto the cornea.

Advancements in refractive surgery have made various lasers safer and more effective for the treatment of hyperopia [3-7]. Excimer lasers allow for a larger optical zone of ablation, more rapid ablation rates, and faster eye scanners. These factors have also been complemented by the use of nomograms to help achieve a more accurate and predictable refractive correction. In the study reported here, we performed vector analysis and evaluated the safety and efficacy of LASIK in hyperopic and hyperopic astigmatic eyes using the Allegretto EX500 excimer laser (Alcon, Fort Worth, TX, USA) equipped with a well-refined nomogram. We also conducted historical analysis to compare our study results to those of existing LASIK platforms based on a literature search from 1998 to 2020 in addition to all excimer modalities approved for hyperopic LASIK by the US Food and Drug Administration. 


\section{METHODS}

\section{Patients}

This retrospective non-comparative study analyzed 379 eyes (181 and 198 right and left eyes, respectively) in 265 consecutive patients with hyperopia or hyperopic astigmatism treated with LASIK using the Allegretto EX500 excimer laser between 1 January 2013 and 24 Apri 2020. The average age ( \pm standard deviation $[\mathrm{SD}]$ ) of the patients was $46.1 \pm 11.7$ (range 18-72) years, and the female to male ratio was 48:52. All surgeries were performed at a single site (Hoopes Vision, Draper, Utah, USA) by four surgeons. Data were collected from Hoopes Vision and retrieved from the SurgiVision DataLink (SurgiVision Consultants Inc, Scottsdale, AR, USA). Patients gave broad consent for the use of de-identified clinical data for research purposes. The study and consent procedure were approved by the Hoopes Vision Ethics Committee and adhered to the tenets of the Declaration of Helsinki. The Biomedical Research Alliance of New York (BRANY) Institutional Review Board approved this retrospective study involving de-identified data (\#A2012-547-823).

Eyes with a stable refraction in which hyperopic correction was performed were included. Eyes with a negative sphere at baseline but which underwent hyperopic astigmatic ablation were also included. The target spherical correction for these cases was near vision. Exclusion criteria were unstable hyperopia, patient age younger than 18 years, dry eye disease, abnormal topography, history of ocular trauma, keratitis, keratoconus, lens opacities, uveitis, glaucoma, and retinal diseases. All patients in the study had a goal of either full correction (refraction of 0 for both sphere and cylinder) or monovision correction ranging from -0.5 to $-2.0 \mathrm{D}$.

A full ophthalmic preoperative examination was performed on all patients, including ocular history, CDVA, slit-lamp examination, manifest refraction, cycloplegic refraction, manual keratometry, and fundus examination.
Postoperative follow-up examinations were performed at 1, 3, 6, 9, and 12 months.

\section{Surgical Protocol}

LASIK was performed using a standard technique. A corneal flap was created using the Intralase iFS femtosecond laser (Johnson and Johnson, New Brunswick, NJ, USA). Corneal ablation was performed using the Allegretto EX500 excimer laser with an optical zone of $6.00-8.90 \mathrm{~mm}$. Flap creation with the iFS Advanced Femtosecond laser was performed at $150 \mathrm{kHz}$ in a raster pattern with bed energy of $0.85 \mu \mathrm{J}$ and side cut energy of $0.6 \mu \mathrm{J}$. Spot and line separations were 6.0 and $6.0 \mu \mathrm{m}$, respectively, for the bed cut and 4.0 and $4.0 \mu \mathrm{m}$, respectively, for the side cut. A hinge position of $90^{\circ}$, hinge angle of $50^{\circ}$, and hinge width of $3.8 \mathrm{~mm}$ were used. A targeted flap size of $9.0 \mathrm{~mm}$ and thickness of $100 \mu \mathrm{m}$ were programmed with a $130^{\circ}$ side cut angle. The eye was then irrigated, and the corneal flap was repositioned. Postoperative therapy included moxifloxacin $0.5 \%$ and prednisolone acetate $1 \%$ drops four times daily for 1 week.

\section{Statistical Analysis}

Refractive outcome was analyzed according to the Standard Graphs for Reporting Refractive Surgery designed by London Vision Clinic (London, UK). Refractive data were analyzed during consecutive follow-up intervals at 1, 3, 6 , 9 , and 12 months. The main parameters measured were the uncorrected distance visual acuity (UDVA), CDVA, manifest refractive spherical equivalent (MRSE), manifest refractive cylinder, refractive axis, target-induced astigmatism, and surgically induced astigmatism. The data were plotted on nine standardized graphs that summarized the safety, efficacy, accuracy, and stability using Microsoft Excel templates (Microsoft Corp., Redmond, WA, USA). Vector analysis was performed based on the methodology provided by Alpins [8] and Eydelman et al. [9].

Statistical comparison between quantitative data was conducted using a $t$-test, and a Fisher 
exact test was used for categorical data. Metaanalysis was conducted on 28 published studies and a summary effect was generated for each analysis. The studies were grouped according to time period based on a noted difference: those before 2005 (1998-2005) and those after 2005 (2005-2020). Articles presenting data on refractive outcomes following LASIK for hyperopic astigmatism were included. Papers that did not present any specific data for refractive outcomes, either within the text or using the standard 9 graphs for reporting refractive outcomes, were excluded. R statistics (version 3.5.0; R Core Team 2018, R Foundation for Statistical Computing, Vienna, Austria) was used to calculate the estimated incidence proportions and variance. The $\mathrm{R}$ package meta was used to calculate pooled estimates for all groups and subgroups. A random-effects model was used without transformation for all analyses. To describe heterogeneity between studies, $I^{2}$ and $\tau^{2}$ statistics were used, where $I^{2}$ is an index of heterogeneity that represents the percentage of the total variance due to variation between studies and $\tau^{2}$ expresses variance between studies in a random-effects meta-analysis.

Devices approved by the US Food and Drug Administration (FDA) and their corresponding reported clinical trials were obtained from the FDA.gov website using the Summary of Safety and Effectiveness Data report, and the premarket approval (PMA) numbers are included. A thorough literature search was performed on Pubmed (National Institute of Health, Bethesda, MD, USA) and Elsevier (Relx, Amsterdam, the Netherlands).

\section{RESULTS}

\section{Study Population}

The mean $( \pm \mathrm{SD})$ preoperative MRSE was + $1.33 \pm 1.10 \mathrm{D}$ (range -1.13 to $+4.38 \mathrm{D}$ ) and the mean sphere was $1.82 \pm 1.28 \mathrm{D}$ (range -0.75 to $6.25 \mathrm{D})$. Eyes with a negative sphere at baseline that were included in the study received a hyperopic astigmatic ablation and were treated for the purposes of monovision and the induction of additional myopia. Patient demographics and refractive outcomes at 3 and 12 months postoperatively are given in Table 1 .

Table 1 Patient demographics for eyes that received LASIK for hyperopia and hyperopic astigmatism

\begin{tabular}{|c|c|c|c|c|c|c|}
\hline & \multicolumn{2}{|c|}{ Preoperative $(n=379)$} & \multicolumn{2}{|c|}{3 months Postop $(n=334)$} & \multicolumn{2}{|c|}{12 months Postop $(n=189)$} \\
\hline & Mean \pm SD & Range & $\overline{M e a n} \pm$ SD & Range & Mean \pm SD & Range \\
\hline $\begin{array}{l}\text { Refractive sphere } \\
\text { (D) }\end{array}$ & $\begin{array}{c}+1.82 \pm \\
1.28\end{array}$ & $\begin{array}{c}-0.75 \text { to } \\
+6.25\end{array}$ & $\begin{array}{c}-0.32 \pm \\
0.81\end{array}$ & $\begin{array}{c}-2.50 \text { to } \\
+2.25\end{array}$ & $\begin{array}{c}-0.25 \pm \\
0.80\end{array}$ & $\begin{array}{c}-2.00 \text { to } \\
+2.00\end{array}$ \\
\hline $\begin{array}{l}\text { Refractive cylinder } \\
\text { (D) }\end{array}$ & $\begin{array}{c}-0.98 \pm \\
1.06\end{array}$ & -5.75 to 0 & $\begin{array}{c}-0.40 \pm \\
0.37\end{array}$ & -2.00 to 0 & $\begin{array}{c}-0.44 \pm \\
0.34\end{array}$ & -1.5 to 0 \\
\hline MRSE $\pm S D(D)$ & $\begin{array}{c}+1.33 \pm \\
1.10\end{array}$ & $\begin{array}{c}-1.13 \text { to } \\
+4.38\end{array}$ & $\begin{array}{c}-0.52 \pm \\
0.78\end{array}$ & $\begin{array}{c}-2.50 \text { to } \\
+1.50\end{array}$ & $\begin{array}{c}-0.46 \pm \\
0.79\end{array}$ & $\begin{array}{c}-2.13 \text { to } \\
+1.25\end{array}$ \\
\hline CDVA (log MAR) & $0.01 \pm 0.06$ & -0.12 to 0.48 & $0.00 \pm 0.09$ & -0.12 to 0.78 & $\begin{array}{c}-0.01 \pm \\
0.06\end{array}$ & -0.12 to 0.30 \\
\hline UDVA (log MAR)* & - & - & $0.04 \pm 0.15$ & -0.12 to 0.90 & $0.03 \pm 0.11$ & -0.12 to 0.48 \\
\hline
\end{tabular}

$D$ Diopters, $S D$ standard deviation, MRSE manifest refractive spherical equivalent, $U D V A$ uncorrected distance visual acuity, $C D V A$ corrected distance visual acuity

${ }^{*}$ Average excludes eyes with monovision 


\section{Efficacy and Safety}

At 3 months postoperatively, $142(66 \%)$ and 207 (96\%) of 216 eyes, excluding monovision, had a UDVA better than 20/20 and 20/40, respectively. At 12 months, 81 (69\%) and 114 (97\%) of 117 eyes, excluding monovision, had a postoperative UDVA 20/20 and 20/40 or better, respectively (Fig. 1a). At 3 months, 145 (67\%) eyes had a postoperative UDVA the same as or better than the preoperative CDVA on Snellen lines, and $189(88 \%)$ were within one line of the CDVA. Eighty-six (74\%) eyes had a UDVA the same or better on Snellen lines at 1 year and 108 $(92 \%)$ were within one line of CDVA (Fig. 1b). The efficacy index, defined as the ratio between the mean postoperative and preoperative 3 months UDVA, was 0.87 at 3 months and 0.93 at 12 months. Of 334 eyes, 226 (68\%) had no change in Snellen lines, and only five eyes lost two or more lines at 3 months. Only two of 189 eyes lost two or more Snellen lines of CDVA 1 year postoperatively, while 178 (94\%) had either no change or a gain of lines of CDVA (Fig. 1c). The safety index at 12 months, defined as the ratio of the mean postoperative and preoperative CDVA, was 1.03.

\section{Accuracy and Stability}

When evaluating the attempted and achieved spherical equivalents postoperatively, there was a strong correlation at both 3 months $(0.90)$ and 12 months (0.86) postoperatively (Fig. 1d). At 3 and 12 months postoperatively, 317 (95\%) and $181(96 \%)$ of eyes were within $\pm 1.00 \mathrm{D}$ of the intended target, respectively (Fig. 1e). Over 12 months, only $19 \%$ of eyes had a $>0.50 \mathrm{D}$ change (Fig. 1f).

\section{Correction of Astigmatism}

We found that $261(78 \%)$ eyes had $\leq 0.50 \mathrm{D}$ and $316(95 \%)$ of 334 eyes had $\leq 1.00 \mathrm{D}$ of astigmatism at 3 months. Similarly, at 12 months postoperatively, 143 (76\%) eyes had $\leq 0.50 \mathrm{D}$, and $183(97 \%)$ of 189 eyes had $\leq 1.00 \mathrm{D}$ of astigmatism. There was a strong correlation between the target and surgically induced astigmatism vectors according to linear regression analysis (Fig. $1 \mathrm{~g}, \mathrm{~h}$ ). The angle of error was within $\pm 15^{\circ}$ of the target angle in 221 (77\%) and 107 (66\%) eyes at 3 and 12 months, respectively (Fig. 1I).

\section{Review of Current Literature}

A compilation of studies dating back to 1998 and FDA published clinical trials for LASIK platforms approved for the treatment of hyperopia and hyperopic astigmatism are listed in Tables 2 and 3, respectively. We performed a meta-analysis using these data to assess for changes in efficacy over time. Literature published before 2005 reported a postoperative UDVA of $20 / 20$ or better in $32 \%$ of eyes, compared to $68 \%$ of eyes in those published after 2005 (Fig. 2a). A similar trend was present to a smaller degree in studies published by the FDA (Fig. 2b). In the literature, studies prior to 2005 reported achieving $20 / 40$ or better with an average of $85 \%$, whereas those after 2005 reported 98\% (Fig. 3a). In the FDA published data, this difference was only $1 \%$ between the two time points (Fig. 3b).

We present a meta-analysis of the accuracy outcomes defined as a MRSE within $\pm 0.50 \mathrm{D}$ of the intended target (Fig. 4a, b). Notably, published studies reported $45 \%$ versus $76 \%$ of eyes that achieved an MRSE within \pm 0.50 D before and after 2005, respectively. In the FDA data, this discrepancy was absent between the two time points as the percent change was $1 \%$.

\section{DISCUSSION}

In our historical analysis and overview of various platforms approved for the treatment of hyperopic astigmatism, we were able to highlight the advancements over time, most notably before and after 2005. A trend towards better efficacy was uncovered from our meta-analysis, as shown in Figs. 2-4. Figure 5 displays a historical trend of efficacy data from FDA-approved lasers in comparison to our current study.

Despite recent advancements and the use of refined nomograms, when we compare our 


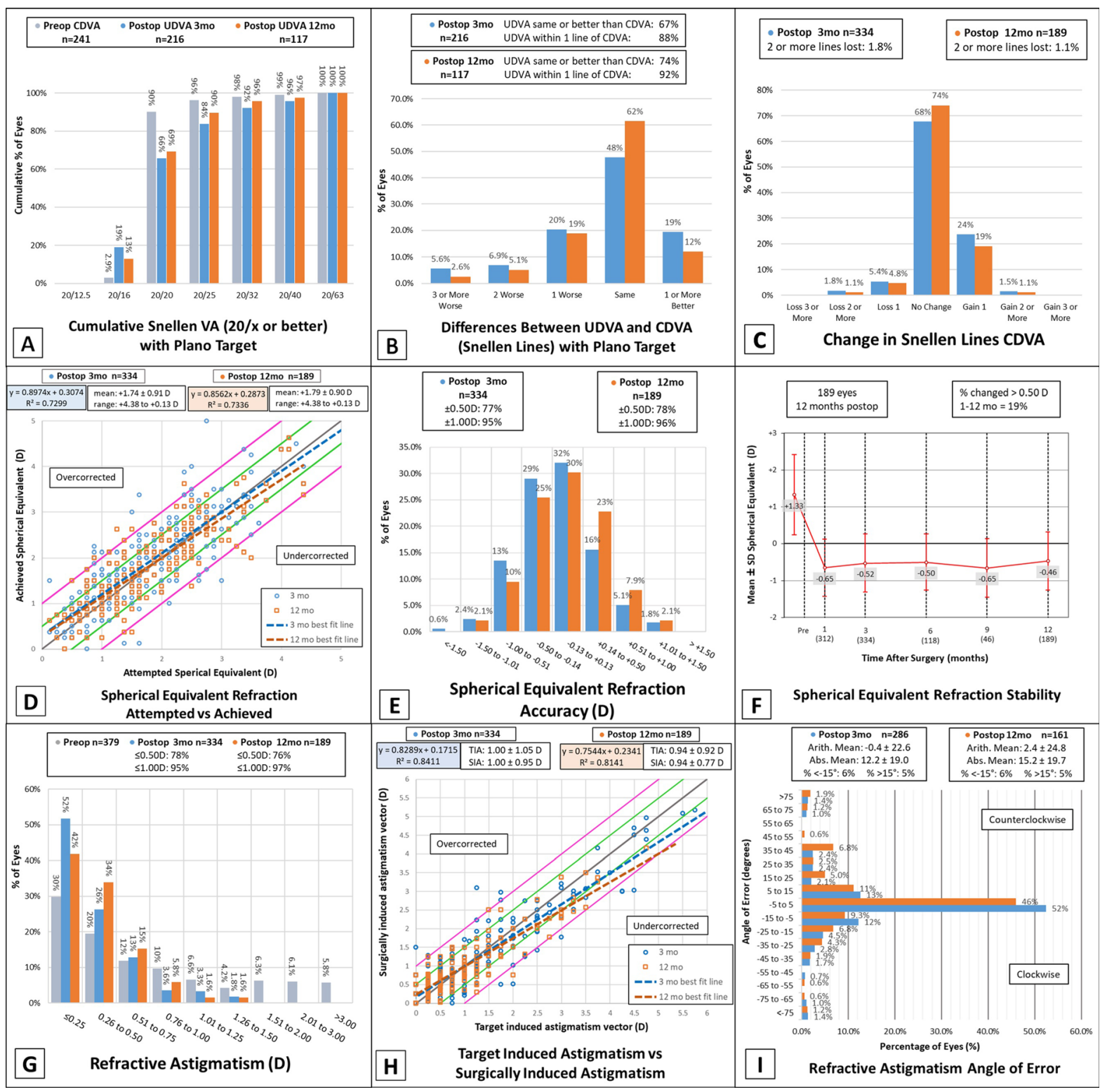

Fig. 1 Nine standard graphs for reporting refractive surgery outcomes for hyperopic treatments utilizing the Allegretto EX500 excimer laser at 3 and 12 months postoperatively. CDVA Corrected distance visual acuity,

results to existing platforms for topography and wavefront-guided LASIK for the treatment of myopia, it is evident that the treatment of hyperopia lags behind and has not reached its peak [10]. The efficacy of myopic treatment is near $90 \%$ for eyes, achieving a UDVA $20 / 20$ or better after surgery, significantly higher than
$D$ diopters, Postop postoperative, Preop preoperative, SIA surgically induced astigmatism, TIA target induced astigmatism, UDVA uncorrected distance visual acuity, $V A$ visual acuity

the average 68 and $64 \%$ we obtained for hyperopic treatment from our meta-analysis for the published literature and FDA clinical trials, respectively. A significant limitation in hyperopic treatment is the angle $\kappa$, which is the angle formed between the visual axis and the pupillary axis, identified clinically by the 


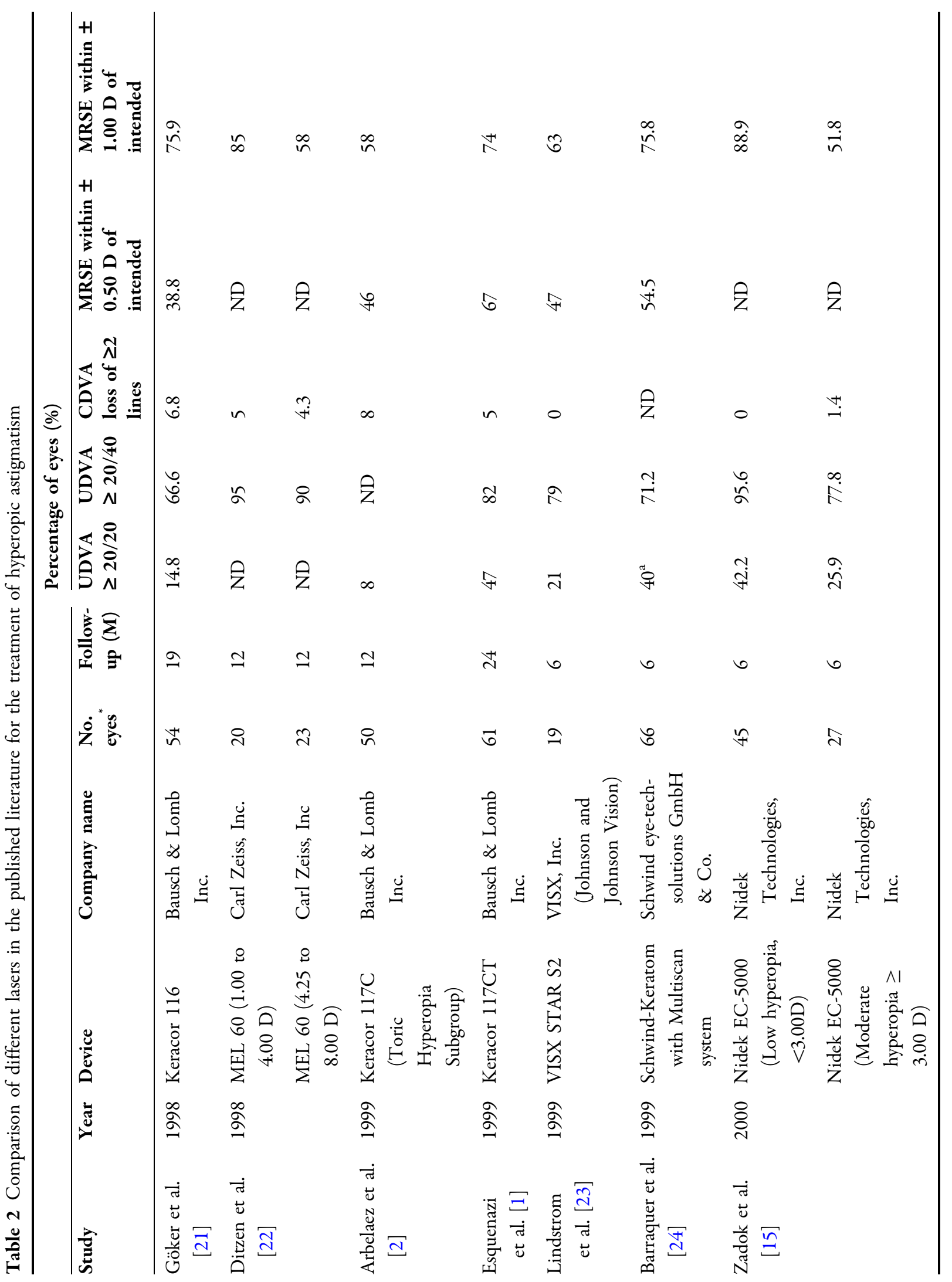




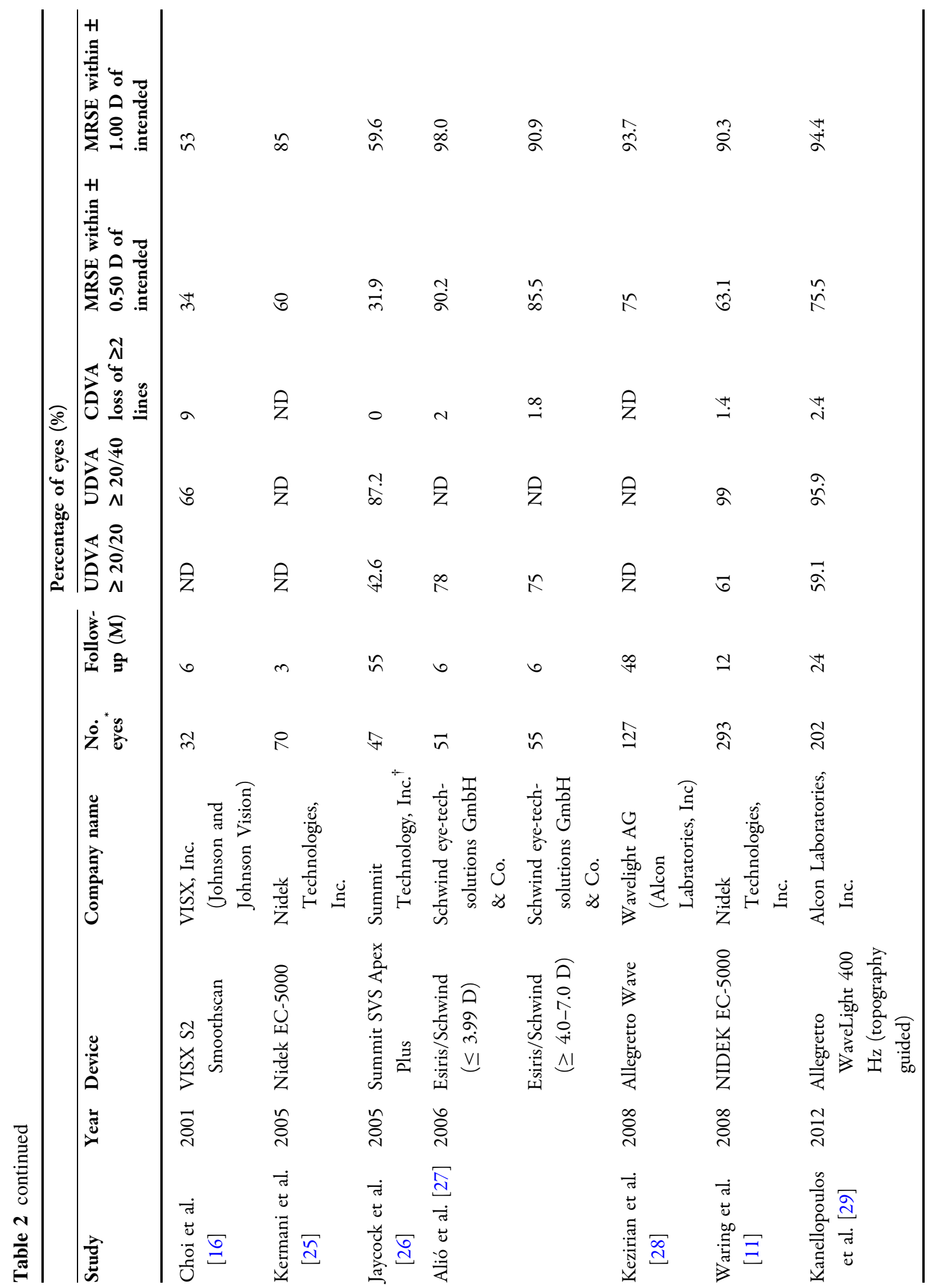




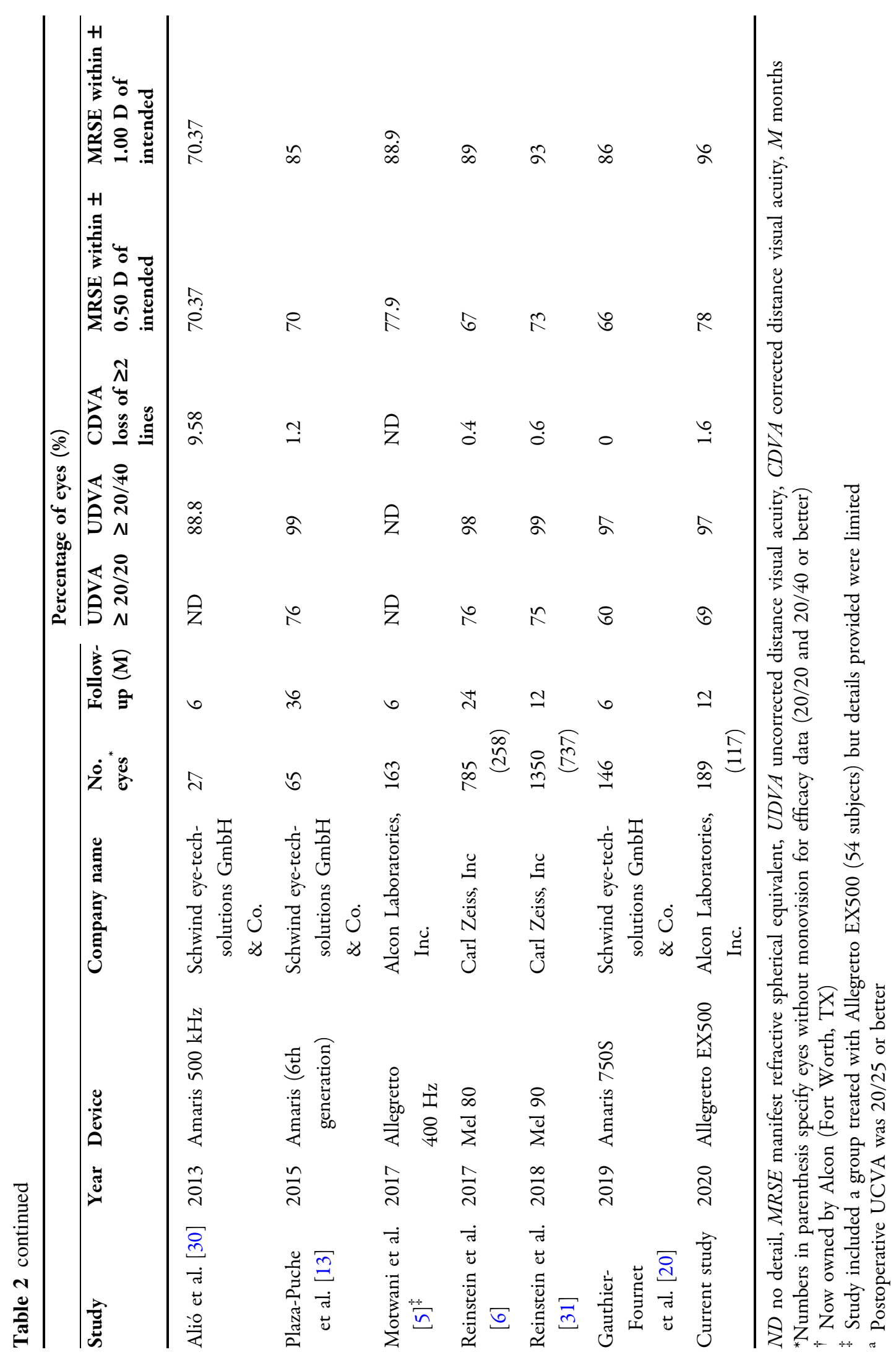


Table 3 Comparison of different lasers from FDA clinical studies for the treatment of hyperopic astigmatism

\begin{tabular}{|c|c|c|c|c|c|c|c|c|c|}
\hline \multirow[t]{2}{*}{ Study } & \multirow[t]{2}{*}{ Year } & \multirow[t]{2}{*}{ Device } & \multirow{2}{*}{$\begin{array}{l}\text { No. } \\
\text { eyes }\end{array}$} & \multirow{2}{*}{$\begin{array}{l}\text { Follow- } \\
\text { up }(\mathbf{M})\end{array}$} & \multicolumn{5}{|c|}{ Percentage of eyes (\%) } \\
\hline & & & & & $\begin{array}{l}\text { UDVA } \\
20 / 20 \\
\text { or } \\
\text { Better }\end{array}$ & $\begin{array}{l}\text { UDVA } \\
20 / 40 \\
\text { Or } \\
\text { Better }\end{array}$ & $\begin{array}{l}\text { CDVA } \\
\text { loss of } \\
\geq 2 \\
\text { lines }\end{array}$ & $\begin{array}{l}\text { MRSE } \\
\text { within } \pm \\
0.50 \mathrm{D} \\
\text { of } \\
\text { intended }\end{array}$ & $\begin{array}{l}\text { MRSE } \\
\text { within } \pm \\
1.00 \mathrm{D} \\
\text { of } \\
\text { intended }\end{array}$ \\
\hline $\begin{array}{l}\text { FDA Summit } \\
\text { Technology } \\
\text { PMA: P930034/S12 } \\
\text { (Hyperopic PRK up } \\
\text { to }+4 \mathrm{D})\end{array}$ & 1999 & $\begin{array}{l}\text { SVS Apex Plus } \\
\text { Excimer Laser } \\
\text { Workstation, } \\
\text { Emphasis discs } \\
\text { (K and L), and } \\
\text { axicon }\end{array}$ & $\begin{array}{l}165 \\
(144)\end{array}$ & 12 & 45.8 & 91.7 & 2.8 & 55.8 & 84.2 \\
\hline $\begin{array}{l}\text { Ladar FDA: PMA } \\
\text { 970043/S7 } \\
\text { (Hyperopic Cohort) }\end{array}$ & 2000 & $\begin{array}{l}\text { LADARVision } \\
\text { Excimer Laser } \\
\text { System }\end{array}$ & $\begin{array}{l}121 \\
(103)\end{array}$ & 9 & 47.6 & 95.1 & 3.4 & 67.5 & 88.3 \\
\hline $\begin{array}{l}\text { Ladar FDA: } \\
\text { PMA 970043/S7 } \\
\text { (Hyperopic } \\
\text { Astigmatic } \\
\text { Cohort) }\end{array}$ & 2000 & $\begin{array}{l}\text { LADARVision } \\
\text { Excimer Laser } \\
\text { System }\end{array}$ & $\begin{array}{l}94 \\
(83)\end{array}$ & 9 & 51.8 & 95.2 & 4.4 & 70.2 & 91.5 \\
\hline $\begin{array}{l}\text { VISX FDA } \\
\text { PMA: P930016/S12 }\end{array}$ & 2001 & $\begin{array}{l}\text { VISX STAR } \\
\text { Excimer Laser } \\
\text { System Models } \\
\text { S2 and S3 }\end{array}$ & $\begin{array}{l}144 \\
(133)\end{array}$ & 6 & 48.1 & 97.0 & 3.8 & 76.4 & 91.0 \\
\hline $\begin{array}{l}\text { Allegretto FDA } \\
\text { PMA: P030008 }\end{array}$ & 2003 & $\begin{array}{l}\text { Wavelight } \\
\text { Allegretto } \\
\text { Wave } \\
(200-400 \mathrm{~Hz})\end{array}$ & $98(80)$ & 12 & 67.5 & 98.8 & 1.0 & 65.3 & 90.8 \\
\hline $\begin{array}{l}\text { VISX FDA } \\
\text { PMA: 930016/S17 }\end{array}$ & 2004 & VISX STAR S4 & 27 & 12 & 77.8 & 92.6 & ND & 81.5 & 92.6 \\
\hline $\begin{array}{l}\text { Ladar FDA } \\
\text { PMA: P970043/S20 }\end{array}$ & 2006 & $\begin{array}{l}\text { LADARVision } \\
4000 \text { and } \\
\text { LADAR6000 } \\
\text { Excimer Laser } \\
\text { Systems }\end{array}$ & $\begin{array}{l}138 \\
(128)\end{array}$ & 9 & 58.7 & 94.2 & 31.9 & 65.2 & 89.1 \\
\hline $\begin{array}{l}\text { NIDEK FDA } \\
\text { PMA: P970053/S9 }\end{array}$ & 2006 & Nidek EC-5000 & 279 & 12 & 60.9 & 99.3 & 20.1 & 63.08 & 90.3 \\
\hline $\begin{array}{l}\text { MEL } 80 \text { FDA } \\
\text { PMA: P060004/S1 }\end{array}$ & 2011 & $\begin{array}{l}\text { MEDITEC } \\
\text { MEL } 80\end{array}$ & 153 & 12 & 66.7 & 96.7 & 5.2 & 78.4 & 92.2 \\
\hline
\end{tabular}


Table 3 continued

\begin{tabular}{|c|c|c|c|c|c|c|c|c|c|}
\hline \multirow[t]{2}{*}{ Study } & \multirow[t]{2}{*}{ Year } & \multirow[t]{2}{*}{ Device } & \multirow{2}{*}{$\begin{array}{l}\text { No. } \\
\text { eyes }\end{array}$} & \multirow{2}{*}{$\begin{array}{l}\text { Follow- } \\
\text { up }(\mathbf{M})\end{array}$} & \multicolumn{5}{|c|}{ Percentage of eyes (\%) } \\
\hline & & & & & $\begin{array}{l}\text { UDVA } \\
20 / 20 \\
\text { or } \\
\text { Better }\end{array}$ & $\begin{array}{l}\text { UDVA } \\
20 / 40 \\
\text { Or } \\
\text { Better }\end{array}$ & $\begin{array}{l}\text { CDVA } \\
\text { loss of } \\
\geq 2 \\
\text { lines }\end{array}$ & $\begin{array}{l}\text { MRSE } \\
\text { within } \pm \\
0.50 \mathrm{D} \\
\text { of } \\
\text { intended }\end{array}$ & $\begin{array}{l}\text { MRSE } \\
\text { within } \pm \\
1.00 \mathrm{D} \\
\text { of } \\
\text { intended }\end{array}$ \\
\hline VISX FDA & 2017 & STAR S4 IR & 131 & 12 & 65.6 & 93.9 & 3.1 & 63.4 & 83.2 \\
\hline PMA P930016/S48 & & $\begin{array}{l}\text { Excimer Laser } \\
\text { and iDesign } \\
\text { Advanced } \\
\text { Wavescan } \\
\text { Studio System }\end{array}$ & & & & & & & \\
\hline
\end{tabular}

$N D$ no detail, $M R S E$ manifest refractive spherical equivalent, $U D V A$ uncorrected distance visual acuity, $C D V A$ corrected distance visual acuity, $M$ months, FDA U.S. Food and Drug Administration, PMA premarket approval

${ }^{*}$ Numbers in parenthesis specify eyes without monovision for efficacy data (20/20 and 20/40 or better)

displacement of the corneal light reflex from the center of the pupil. The larger this angle, the more nasal the light reflex falls. This limits treatment since ablation is performed around the pupil instead of around the angle $\kappa$, potentially explaining why some patients lose Snellen lines postoperatively. Visual regression may also be attributed to the thickening of the epithelium and stromal remodeling after surgery once the periphery has been ablated.

While more modern lasers appear to increase safety and efficacy in the treatment of hyperopia, with MRSE up to $6.0 \mathrm{D}$, it is important to acknowledge the persistent limitations in these systems [5, 11-13]. For example, Cobo-Soriano et al. found a significant decline in predictability beyond $4.0 \mathrm{D}$ [14], and Esquenazi and Mendoza concluded that safety and predictability reduced over $5.0 \mathrm{D}$ [1]. In the 2000 study by Zadok et al., a prominent drop in predictability from $88.9 \%$ in the low hyperopic group $(<3.00 \mathrm{D})$ to $51.8 \%$ in the moderate hyperopic $(\geq 3.00 \mathrm{D})$ group can be seen [15]. Similarly, Choi et al. reported that in eyes ranging from +5.00 to $8.75 \mathrm{D}, 50 \%$ of eyes lost two lines on CDVA postoperatively [16]. In our study, the preoperative sphere of those eyes followed up to 12 months ranged from -0.75 to $+4.25 \mathrm{D}$, and the MRSE ranged from -0.88 to $+4.38 \mathrm{D}$. We stratified these data into low $(n=174,0-2.99 \mathrm{D})$ and moderate $(n=15$, 3.00-5.00 D) degrees of hyperopia to further assess the 1-year refractive outcomes after LASIK (Table 4). Although the statistical analysis revealed no significant difference between the two groups, the results seemed to be trending towards significance $(p=0.07$ for $20 / 20$ or better). This outcome may have been affected by the small sample size of the group with a moderate degree of hyperopia; therefore, a larger sample size may have revealed that safety and efficacy were indeed better in eyes under + 2.99 D.

Even modern excimer lasers equipped with extended optical zones and enhanced ablation profiles are limited in terms of efficacy in the treatment of moderate to high degrees of hyperopia. In the FDA study which led to the approval of the Allegretto Wavelight for treatment of hyperopia, only 24 eyes between + 3.00 and $+4.00 \mathrm{D}$ and 16 eyes between +4.01 and $+5.00 \mathrm{D}$ were assessed for efficacy. Although the study approved the reduction or elimination of hyperopic refractive errors with a maximum MRSE of $+6.00 \mathrm{D}$, only seven eyes between +5.00 and $+6.00 \mathrm{D}$ were included in the study at the 6-month time point in which the stratification was presented. Table 5 

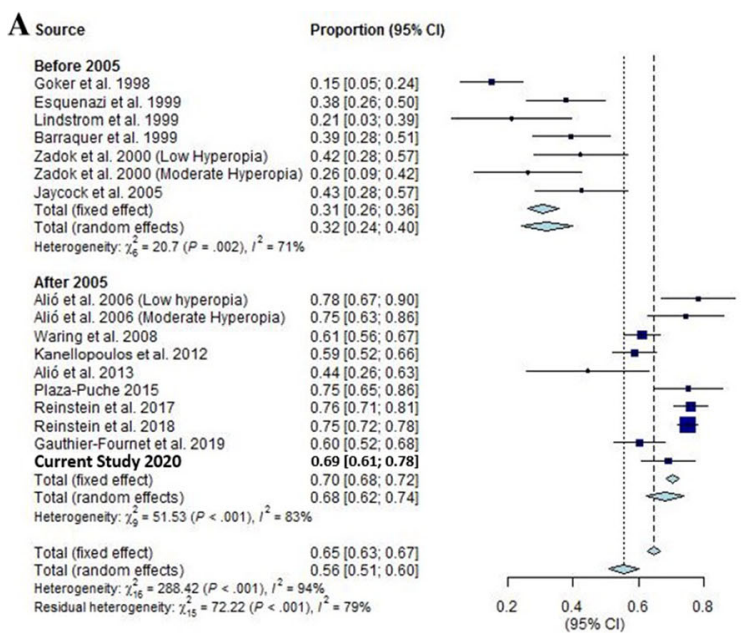

B

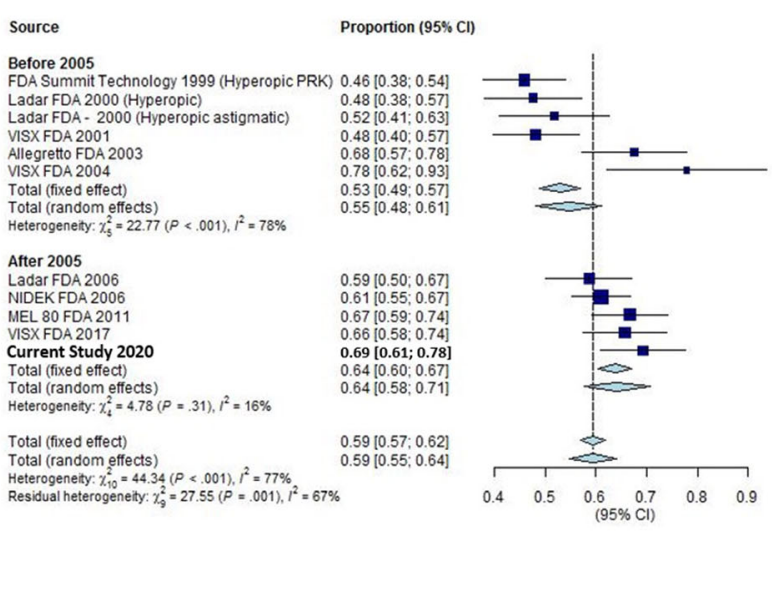

Fig. 2 Meta-analysis of the published literature (a) and of U.S. Food and Drug Administration (FDA) clinical studies (b) for postoperative UDVA $20 / 20$ or better. CI Confidence interval

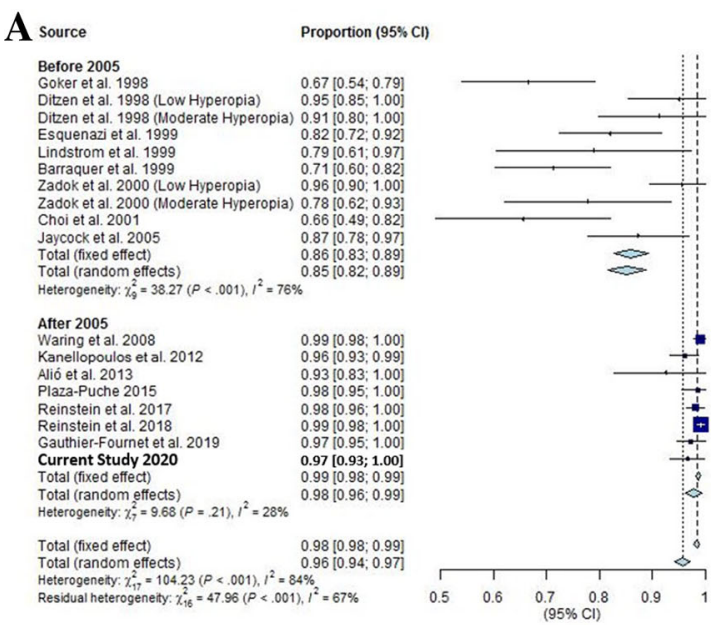

B

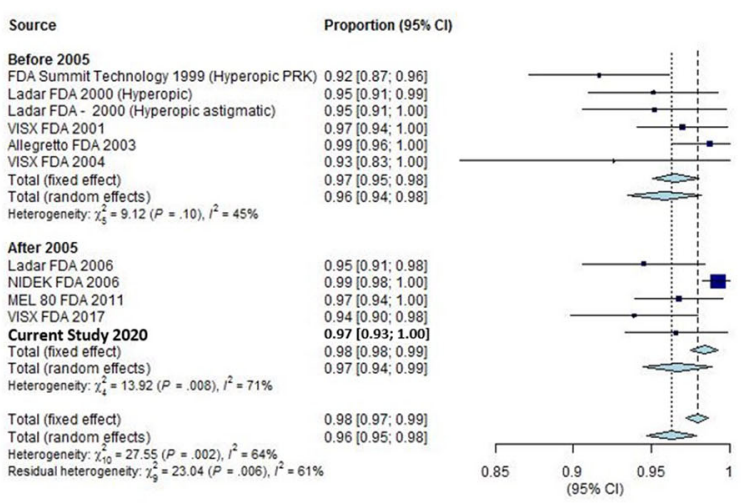

Fig. 3 Meta-analysis of the published literature (a) and of U.S. FDA clinical studies (b) for postoperative UDVA 20/40 or better

illustrates a comparison of the efficacy and accuracy between our study and FDA-approved platforms while accounting for the preoperative MRSE. Better visual outcomes are observed in most instances in eyes with a preoperative MRSE $\leq+4.00 \mathrm{D}$.

Our results were similar to those reported by Kanellopoulos et al. [17] and Motwani and Pei [5] who included an assessment of the Allegretto excimer laser platform using both $400 \mathrm{~Hz}$ and EX500 systems. Motwani and Pei reported that although the rate of regression was low in both lasers, it was significantly less in the EX500 system. In our study, only $1.6 \%$ of patients experienced a loss of two or more lines of CDVA at 12 months postoperatively. This rate of regression was among the lowest in the published studies we analyzed. In fact, a trend towards less regression can be appreciated in studies after 2005 with the exception of $9.6 \%$ reported by Alio et al. in 2013 (Table 2).

Our results also agree with reports by Waring et al., Reinstein et al., Plaza-Puche et al., as well as the FDA clinical trial that approved the Allegretto EX500 platform [11-13, 18]. In our study, we achieved a UDVA of 20/20 or better in 


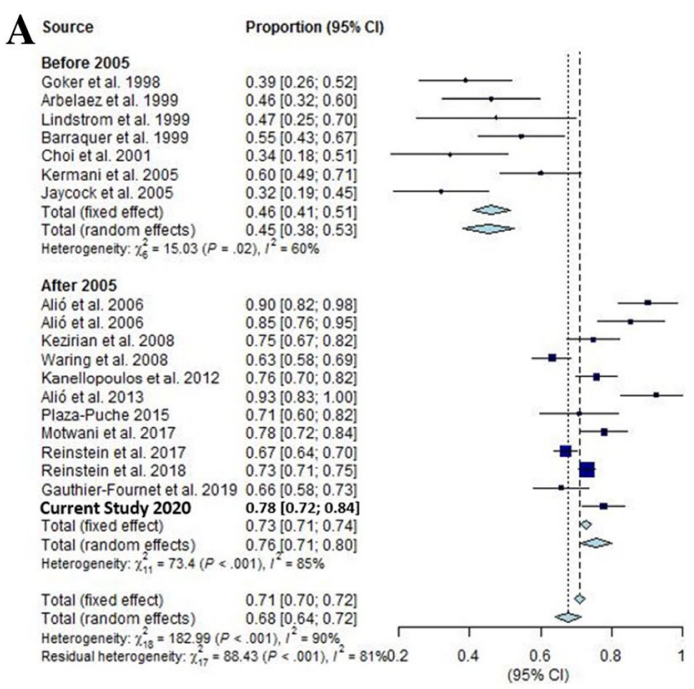

B

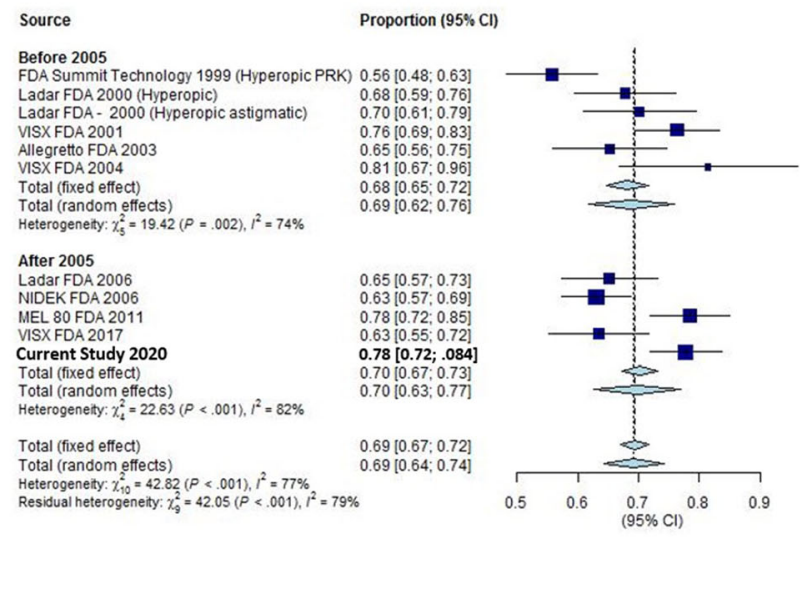

Fig. 4 Meta-analysis of the published literature (a) and of the FDA clinical studies (b) for manifest refractive spherical equivalent within $\pm 0.50 \mathrm{D}$

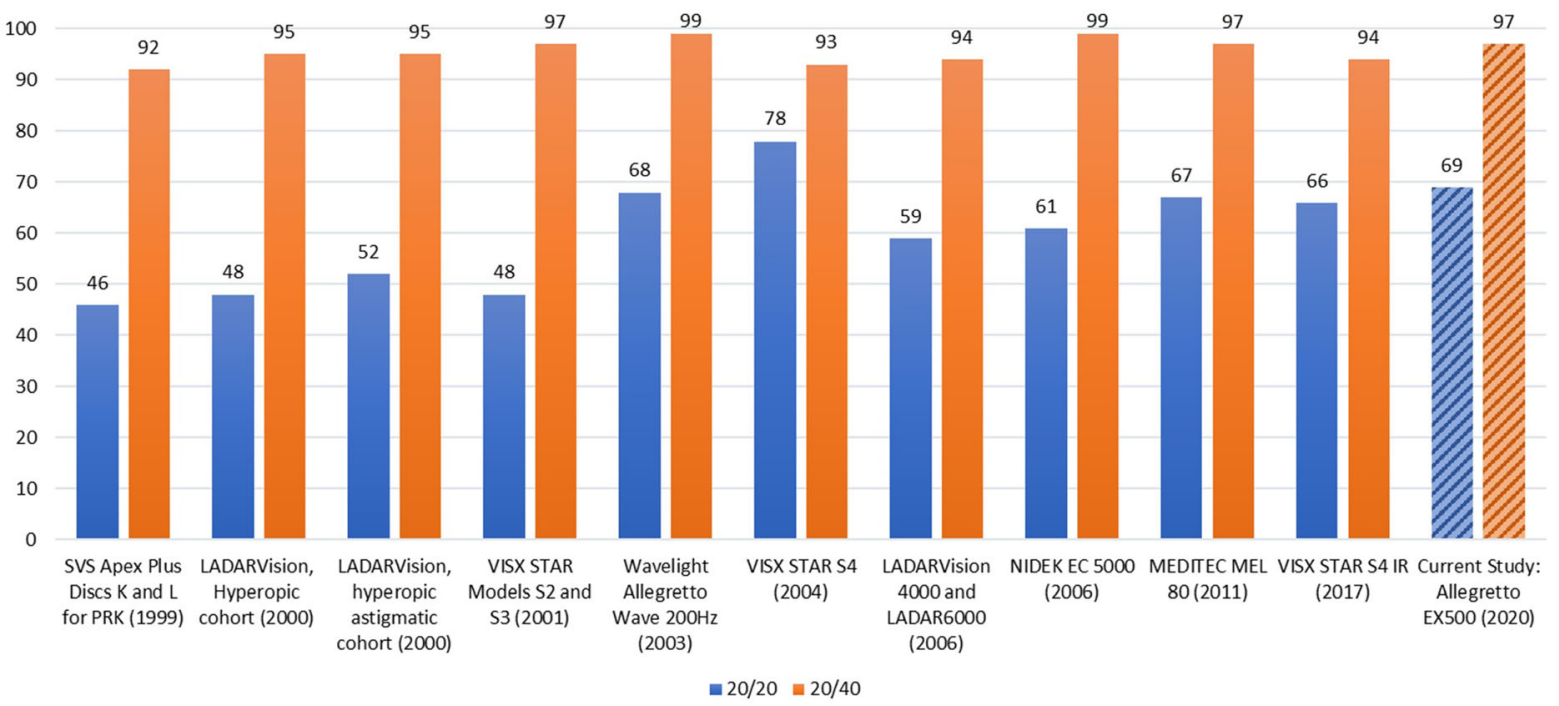

Fig. 5 A historical trend of efficacy data (20/20 or better) from FDA-approved lasers for laser-assisted in-situ keratomileusis treatment of hyperopia and hyperopic astigmatism from 1999 to 2017 versus current study

$69 \%$ of eyes at 12 months; however, our surgeons believe that this value underestimates the true results seen in our patient population. Within the past two decades, the literature reveals that various lasers were sufficient in correcting the spherical equivalent to within \pm $1.00 \mathrm{D}$ in $51.8-98 \%$ of eyes (Table 2). Our current study found that the Allegretto EX500 excimer laser successfully achieved an MRSE correction to within $\pm 1.00 \mathrm{D}$ of target in $96 \%$ of eyes, supporting the accuracy of this platform. To our best knowledge, supported by our literature review, the FDA trial concerning the approval of the Allegretto EX500 (PMA\#: P030008) was simply an extension of the trial that utilized the $200 \mathrm{~Hz}$ excimer laser. Similarly, the study published by Kezirian et al. as an extension of the FDA report utilized the 
Table 4 Refractive outcome parameters for each diopter bin

\begin{tabular}{llll}
\hline Preop MRSE & $\mathbf{0}$ to $+\mathbf{2 . 9 9} \mathbf{D}$ & $\mathbf{+ 3 . 0 0}$ to $+\mathbf{5 . 0 0} \mathbf{D}$ & $\boldsymbol{p}$ value \\
\hline Eyes & 174 & 15 & - \\
Preop MRSE \pm SD & $+1.16 \pm 0.92$ & $+3.63 \pm 0.47$ & $<0.00001$ \\
Postop spherical equivalent (D) & $-0.54 \pm 0.76$ & $+0.38 \pm 0.55$ & $<0.00001$ \\
Post-operative UDVA (logMAR) & $0.02 \pm 0.10$ & $0.07 \pm 0.14$ & 0.20 \\
Post-operative CDVA (logMAR) & $-0.02 \pm 0.06$ & $0.02 \pm 0.10$ & 0.13 \\
UDVA 20/20 or better, n/N (\%) & $74 / 102(73 \%)$ & $7 / 15(47 \%)$ & 0.07 \\
UDVA 20/40 or better, n/N (\%) & $100 / 102(98 \%)$ & $14 / 15(100 \%)$ & 0.34 \\
Loss of one line CDVA, n/N (\%) & $7 / 174(4 \%)$ & $2 / 15(13 \%)$ & 0.15 \\
Loss of two or more lines CDVA, n/N (\%) & $1 / 174(0.6 \%)$ & $1 / 15(6.7 \%)$ & 0.15 \\
Postop spherical equivalent within 0.50 D of target (\%) & $139 / 174(80 \%)$ & $9 / 15(60 \%)$ & 0.10 \\
Postop spherical equivalent within 1.00 D of target $(\%)$ & $167 / 174(96 \%)$ & $14 / 15(93 \%)$ & 0.49 \\
\hline
\end{tabular}

Postoperative period: 1 year

$S D$ standard deviation, MRSE manifest refractive spherical equivalent, $U D V A$ uncorrected distance visual acuity, $C D V A$ corrected distance visual acuity

Allegretto WAVE $(400 \mathrm{~Hz})$ [28]. Our study is the first to assess the Allegretto EX500 excimer laser with a large sample size at 12 months.

Modern excimer laser refractive surgery is an exciting field in ophthalmology given its advancing technology and trend towards improved visual outcomes. Other excimer lasers, such as the Schwind Amaris laser (Schwind eye-tech-solutions, Kleinostheim, Germany), a flying-spot excimer laser similar to the Wavelight Allegretto with a pulse repetition rate of $500-1050 \mathrm{~Hz}$, have also shown promising results $[13,19,20]$. The wavefront-guided Visx iDesign (VISX Inc., Santa Clara, CA, USA) is another modern technology that Moshirfar et al. found to achieve a postoperative UDVA equal to or better than the preoperative CDVA in 69 and $65 \%$ of eyes at 3 and 12 months, postoperatively [10]. These outcomes were consistent with those of our current study on the Allegretto EX500. However, Moshirfar et al. found that when comparing the two platforms, the Allegretto system had a mean postoperative UDVA significantly better than that of the Visx [20].
The retrospective nature and the loss to follow-up of some of our patients are limitations of the study. We recommend the use of a longterm, prospective study to determine the refractive outcomes of LASIK on hyperopic astigmatism. This would be especially useful in measuring the long-term trajectory of refractive regression. Additionally, the inclusion of both eyes in patients with bilateral treatments may introduce additional underlying confounding factors that could be limited by using outcome data from a single, randomized eye in these patients.

In 2003, the FDA approved the Allegretto platform for LASIK surgery. In 2011, they approved an increased pulse frequency of the Wavelight Allegretto laser system from 400 to $500 \mathrm{~Hz}$ for the reduction or elimination of hyperopic refractive errors up to $+6.00 \mathrm{D}$ of sphere with and without astigmatic refractive errors up to $5.00 \mathrm{D}$. Since then, the Allegretto EX500 excimer laser has seen further improvement. 
Table 5 Comparison of efficacy variables stratified by preoperative MRSE for FDA data vs. current study

\begin{tabular}{|c|c|c|c|c|c|c|c|c|c|c|}
\hline & \multicolumn{5}{|c|}{ MRSE +3.01 to $+4.00 \mathrm{D}$} & \multicolumn{5}{|c|}{ MRSE +4.01 to $+5.00 \mathrm{D}$} \\
\hline & $\begin{array}{l}\text { No. } \\
\text { eyes }\end{array}$ & $\begin{array}{l}\text { UDVA } \\
20 / 20 \text { or } \\
\text { better (\%) }\end{array}$ & $\begin{array}{l}\text { UDVA } \\
20 / 40 \text { or } \\
\text { better (\%) }\end{array}$ & $\begin{array}{l}\text { MRSE } \\
\pm 0.50 \\
\text { D (\%) }\end{array}$ & $\begin{array}{l}\text { MRSE } \\
\pm 1.00 \\
\text { D (\%) }\end{array}$ & $\begin{array}{l}\text { No. } \\
\text { eyes }\end{array}$ & $\begin{array}{l}\text { UDVA } \\
20 / 20 \text { or } \\
\text { better (\%) }\end{array}$ & $\begin{array}{l}\text { UDVA } \\
20 / 40 \text { or } \\
\text { better (\%) }\end{array}$ & $\begin{array}{l}\text { MRSE } \\
\pm 0.50 \\
\text { D (\%) }\end{array}$ & $\begin{array}{l}\text { MRSE } \\
\pm 1.00 \\
\text { D (\%) }\end{array}$ \\
\hline $\begin{array}{l}\text { Allegretto } \\
\text { wavelight } \\
(6 \mathrm{~m} .)\end{array}$ & 24 & 37.5 & 91.7 & 71.4 & 85.7 & 16 & 50.0 & 93.8 & 62.5 & 100 \\
\hline $\begin{array}{r}\text { MEL } 80 \\
(9 \mathrm{~m} .)\end{array}$ & 32 & 75.0 & 100 & 78.1 & 96.9 & 24 & 50.0 & 100 & 66.7 & 87.5 \\
\hline $\begin{array}{l}\text { LADAR } \\
4000 \text { and } \\
6000 \\
(6 \mathrm{~m} .)^{*}\end{array}$ & 39 & 35.9 & 87.2 & 51.3 & 74.4 & 36 & 27.8 & 91.7 & 52.8 & 72.2 \\
\hline $\begin{array}{l}\text { VISX STAR } \\
4 \text { with } \\
\text { IDesign } \\
(12 \mathrm{~m} .)\end{array}$ & 22 & 54.5 & 95.5 & 68.2 & 81.8 & 23 & 43.5 & 73.9 & 39.1 & 56.5 \\
\hline $\begin{array}{l}\text { Current } \\
\text { study } \\
(12 \mathrm{~m} .)\end{array}$ & 11 & 55.0 & 100 & 63.6 & 90.9 & 4 & 25.0 & 75.0 & 50.0 & 100 \\
\hline
\end{tabular}

MRSE manifest refractive spherical equivalent, $U D V A$ uncorrected distance visual acuity, $m$ months

${ }^{*}$ MRSE range is from +3.00 to $+3.99 \mathrm{D}$ and +4.00 to $+5.00 \mathrm{D}$

\section{CONCLUSION}

Our historical analysis of various excimer laser platforms has revealed significant advancements in safety, efficacy, predictability, and rates of regression over the past two decades, including a noteworthy shift after 2005. Perhaps the optimized ablation profiles, enhanced repetition rates, and advanced tracking systems to keep up with the fastest eye movements have contributed to this positive trend. Nonetheless, a deficiency in the treatment of hyperopic astigmatism remains evident compared to the treatment of myopia which may be due to the surgical technique involving ablation of the corneal periphery and the induction of central steepening. Although the refractive treatment of hyperopia has limitations, our study-as well as the scientific literature-demonstrate the significant improvements seen over the past 15 years.

\section{ACKNOWLEDGEMENTS}

We thank the participants of the study.

Funding. This study was funded by an unrestricted grant from Research to Prevent Blindness (RPB), 360 Lexington Avenue, 22nd Floor New York, NY 10017. No support was received for the publication of this article.

Authorship. All named authors meet the International Committee of Medical Journal Editors (ICMJE) criteria for authorship for this article, take responsibility for the integrity of the work as a whole, and have given their 
approval for this version to be published. We thank Andrew C. Thomson, Tanisha Martheswaran, Shannon McCabe, MD, and Yasmyne Ronquillo, MD, for assisting in editing and submitting the manuscript.

Authorship contributions. MM: study concept, design, analysis, critical revision, and supervision; AM: writing the manuscript and analysis; WW: data collection, analysis, and critical revision of the manuscript; CM: statistical analysis; RAS: data collection and writing the manuscript); $\mathrm{CN}$ : data analysis and data collection); MT: data collection; PH: supervision, administrative, technical and material support.

Disclosures. All authors declare that they have no conflict of interest.

Compliance with ethics guideline. Patients gave broad consent for the use of de-identified clinical data for research purposes. The study and consent procedure were approved by the Hoopes Vision Ethics Committee and adhered to the tenets of the Declaration of Helsinki. The Biomedical Research Alliance of New York (BRANY) Institutional Review Board approved this retrospective study involving de-identified data (\#A20-12-547-823).

Data availability. The datasets generated during and/or analyzed during the current study are not publicly available on the research site but may be made available from the corresponding author on reasonable request.

Open Access. This article is licensed under a Creative Commons Attribution-NonCommercial 4.0 International License, which permits any non-commercial use, sharing, adaptation, distribution and reproduction in any medium or format, as long as you give appropriate credit to the original author(s) and the source, provide a link to the Creative Commons licence, and indicate if changes were made. The images or other third party material in this article are included in the article's Creative Commons licence, unless indicated otherwise in a credit line to the material. If material is not included in the article's Creative Commons licence and your intended use is not permitted by statutory regulation or exceeds the permitted use, you will need to obtain permission directly from the copyright holder. To view a copy of this licence, visit http://creativecommons.org/licenses/by$\mathrm{nc} / 4.0 /$.

\section{REFERENCES}

1. Esquenazi S, Mendoza A. Two-year follow-up of laser in situ keratomileusis for hyperopia. J Refract Surg. 1999;15(6):648-52.

2. Arbelaez MC, Knorz MC. Laser in situ keratomileusis for hyperopia and hyperopic astigmatism. J Refract Surg. 1999;15(4):406-14.

3. Biscevic A, Pidro A, Pjano MA, Grisevic S, Ziga N, Bohac M. Lasik as a solution for high hypermetropia. Med Arch. 2019;73(3):191-4.

4. Frings A, Druchkiv V, Pose L, Linke SJ, Steinberg J, Katz T. Analysis of excimer laser treatment outcomes and corresponding angle $\kappa$ in hyperopic astigmatism. J Cataract Refract Surg. 2019;45(7): 952-8.

5. Motwani M, Pei R. Treatment of moderate-to-high hyperopia with the WaveLight Allegretto 400 and EX500 excimer laser systems. Clin Ophthalmol. 2017;11:999-1007.

6. Reinstein DZ, Carp GI, Archer TJ, et al. LASIK for the correction of high hyperopic astigmatism with epithelial thickness monitoring. J Refract Surg. 2017;33(5):314-21.

7. Spadea L, Sabetti L, D'Alessandri L, Balestrazzi E. Photorefractive keratectomy and LASIK for the correction of hyperopia: 2-year follow-up. J Refract Surg. 2006;22(2):131-6.

8. Alpins NA. A new method of analyzing vectors for changes in astigmatism. J Cataract Refract Surg. 1993;19(4):524-33.

9. Eydelman MB, Drum B, Holladay J, et al. Standardized analyses of correction of astigmatism by laser systems that reshape the cornea. J Refract Surg. 2006;22:81-95.

10. Moshirfar M, Shah TJ, Skanchy DF, Linn SH, Kang P, Durrie DS. Comparison and analysis of FDA reported visual outcomes of the three latest platforms for LASIK: wavefront guided visx idesign, topography guided wavelight allegro contoura, and 
topography guided nidek EC-5000 CATz. Clin Ophthalmol. 2017;11:135-47.

11. Waring GO, Fant B, Stevens G, et al. Laser in situ keratomileusis for spherical hyperopia and hyperopic astigmatism using the NIDEK EC-5000 excimer laser. J Refract Surg. 2008;24(2):123-36.

12. Reinstein DZ, Carp GI, Archer TJ, Day AC, Vida RS. Outcomes for hyperopic LASIK with the MEL $90{ }^{\circledR}$ excimer laser. J Refract Surg. 2018;34(12):799-808.

13. Plaza-Puche AB, Yebana P, Arba-Mosquera S, Alió JL. Three-year follow-up of hyperopic LASIK using a $500-\mathrm{Hz}$ excimer laser system. J Refract Surg. 2015;31(10):674-82.

14. Cobo-Soriano R, Llovet F, González-López F, Domingo B, Gómez-Sanz F, Baviera J. Factors that influence outcomes of hyperopic laser in situ keratomileusis. J Cataract Refract Surg. 2002;28(9): 1530-8.

15. Zadok D, Maskaleris G, Montes M, Shah S, Garcia V, Chayet A. Hyperopic laser in situ keratomileusis with the Nidek EC-5000 excimer laser. Ophthalmology. 2000;107(6):1132-7.

16. Choi RY, Wilson SE. Hyperopic laser in situ keratomileusis: primary and secondary treatments are safe and effective. Cornea. 2001;20(4):388-93.

17. Kanellopoulos AJ, Conway J, Pe LH. LASIK for hyperopia with the wavelight excimer laser. J Refract Surg. 2006;22(1):43-7.

18. WaveLight Laser Technologie AG. ALLEGRETTO WAVE'“ Scanning Spot LASIK Laser System Patient Information Booklet. 2003. https://www. accessdata.fda.gov/cdrh_docs/pdf3/P030008d.pdf. Accessed 14 July 2020.

19. Arbelaez MC, Vidal C, Mosquera SA. Six-month clinical outcomes after hyperopic correction with the SCHWIND AMARIS Total-Tech laser. J Optom. 2010;3(4):198-205. https://doi.org/10.1016/\$18884296(10)70029-7.

20. Gauthier-Fournet L, Penin F, Arba MS. Six-month outcomes after high hyperopia correction using laser-assisted in situ keratomileusis with a large ablation zone. Cornea. 2019;38(9):1147-53.
21. Göker S, Er H, Kahvecioglu C. Laser in situ keratomileusis to correct hyperopia from +4.25 to +8 . 00 Diopters. J Refract Surg. 1998;14(1):26-30.

22. Ditzen K, Huschka H, Stefan P. Laser in situ keratomileusis for hyperopia. J Cart Refract Surgery. 1998;24(1):42-7.

23. Lindstrom RL, Hardten DR, Houtman DM, Witte B, Preschel N, Chu RY, et al. Six-month results of hyperopic and astigmatic lasik in eyes with primary and secondary hyperopia. Trans Am Ophthalmol Soc. 1999;97:241-55; discussion 255-60.

24. Barraquer CC, Gutiérrez AM. Results of laser in situ keratomileusis in hyperopic compound astigmatism. J Cataract Refract Surg. 1999;25(9):1198-204.

25. Kermani O, Schmeidt K, Oberheide U, Gerten G. Hyperopic laser in situ keratomileusis with 5.5-, 6.5and $7.0-\mathrm{mm}$ optical zones. J Refract Surg. 2005;21(1):52-8.

26. Jaycock PD, O'Brart DPS, Rajan MS, Marshall J. 5 -Year follow-up of LASIK for hyperopia. Ophthalmology. 2005;112(2):191-9.

27. Alió J, Galal A, Ayala MJ, Artola A. Hyperopic LASIK with Esiris/Schwind technology. J Refract Surg. 2006;22(8):772-81.

28. Kezirian GM, Moore CR, et al. Four-year postoperative results of the US ALLEGRETTO WAVE clinical trial for the treatment of hyperopia. J Refract Surg. 2008;24(4):S431-8.

29. Kanellopoulos AJ. Topography-guided hyperopic and hyperopic astigmatism femtosecond laser-assisted LASIK: long-term experience with the $400 \mathrm{~Hz}$ eye-Q excimer platform. Clin Ophthalmol. 2012;6(1):895-901.

30. Alió JL, El Aswad A, Vega-Estrada A, Javaloy J. Laser in situ keratomileusis for high hyperopia ( $>5.0$ diopters) using optimized aspheric profiles: efficacy and safety. J Cataract Refract Surg. 2013;39(4): 519-27.

31. Reinstein DZ, Carp GI, Archer TJ, Day AC, Vida RS. Outcomes for mixed cylinder LASIK with the MEL $90{ }^{\circledR}$ excimer laser. J Refract Surg. 2018;34(10): 672-80. 